\title{
Nietzsche, Wagner e a decadência
}

\author{
Andreas Urs Sommer**
}

Resumo: Fundamental para compreender e caracterizar a filosofia nietzschiana da maturidade, o binômio Wagner/ décadence condensa e expõe, por um lado, a face disruptivonegativa da crítica de Nietzsche à modernidade estética; e, por outro, torna possível uma aplicação pontual da assim chamada "transvaloração dos valores." O presente artigo visa a explicitar tal duplo ponto de vista.

Palavras-chave: Wagner - Nietzsche - décadence transvaloração de todos os valores.

Nietzsche amou Wagner. O embate com suas criações e exigências artísticas foi, para o jovem filólogo, uma experiência libertadora, uma revelação, inclusive. $O$ nascimento da tragédia a partir do espírito da música, última obra filológica e primeiro texto filosófico de Nietzsche, presta um eloquente testemunho disso, em 1872. Sob o manto de um estudo acerca do trágico nos gregos, tal escrito enaltece a força cultural de renovação da obra de arte total de Wagner e coloca-se, pois, totalmente a serviço da temática wagneriana. Em Tribschen, o professor de filologia na Basiléia não era apenas um convidado assíduo e amigo da família, senão que o mestre enxergava, nele, seu destinado apóstolo. No entanto, em meados dos anos de 1870, o estranhamento pessoal e intelectual estabeleceu-se mais e mais, sobretudo porque Nietzsche não queria se contentar com o papel de apóstolo; com efeito, ainda em

\footnotetext{
* Tradução de Fernando R. de Moraes Barros

** Professor da Universidade de Freiburg, Alemanha: Correio eletrônico: sommer@adw.uni-heidelberg.de
} 
1876, ele dedicou sua Quarta consideração extemporânea - de um modo aparentemente servil - ao tema Wagner em Bayreuth, mas reagiu à própria abertura do teatro com um acentuado distanciamento crítico. Somente em 1888 ressurge um escrito que, tal como a Quarta consideração extemporânea, conforme a identificação do título, traz uma única pessoa para o centro das atenções, sendo que tal pessoa é, uma vez mais, Richard Wagner. A primeira parte de minhas explanações consagra-se a essa concisa obra do último ano de produtividade de Nietzsche, intitulada $O$ caso Wagner, ${ }^{1}$ isso porque é nela que o filósofo lida com problema da decadência de forma exemplar. Tentarei, então, numa segunda parte, focalizar de maneira mais precisa o conceito e a crítica de Nietzsche à décadence - o pensador, como se sabe, trata de manter a grafia francesa do termo. Num terceiro momento, sucinto e conclusivo, tenciono ilustrar destacadamente o papel que $O$ caso Wagner e o diagnóstico anti-wagneriano da decadência desempenham na filosofia de Nietzsche em geral.

\section{O Caso Wagner de Nietzsche}

$O$ caso Wagner surgiu entre abril e agosto de 1888, inicialmente em Turim e, depois, em Sils Maria. Já nos meses que o antecederam, Nietzsche sempre voltava a falar a respeito de Wagner e da relação específica que com ele estabelecera. Em 19 de fevereiro de 1888, escreve, pois, a Georg Brandes, dizendo-lhe que as duas Considerações extemporâneas sobre Schopenhauer e Wagner "expuseram mais testemunhos de mim mesmo, sobretudo promessas $\boldsymbol{a}$ mim mesmo, do que uma efetiva psicologia daquele mestre que me é, a um só tempo, tão profundamente aparentado quanto antagôni-

1 Cf. a esse respeito, SOMMER, Andreas Urs. Kommentar zu Nietzsches Der Fall Wagner. In: Götzen-Dämmerung (Historischer und kritischer Kommentar zu Friedrich Nietzsches Werken von der Heidelberger Akademie der Wissenschaften), Bd. 6/1), Berlim/Boston: de Gruyter, 2012, Vol.6/1, pp. 3-194. 
co" (N. 997, KSB 8.260). Por meio de sua carta de 17 de fevereiro de 1888 (N. 519, KGB III 6.157) e de um comentário sobre Ópera e drama, de Wagner, Heinrich Köselitz deu a Nietzsche ensejo para refletir acerca do "estilo dramático" do compositor, o qual "nada mais é do que uma espécie de estilo ruim, inclusive de não-estilo na música" (N. 1000, KSB 8.263). A esse propósito, Nietzsche ainda dá a conhecer aquilo de que derivará, mais tarde, a exigência d'O caso Wagner: "Em realidade, tudo está por ser dito, ou, como inclusive desconfio, tudo permanece quase que impensado nesse âmbito de verdades" (N. 1000, KSB 8.263). Já não é sem tempo, portanto, que alguém pense e se pronuncie a respeito. Segue-se, então, depois desse período, uma omissão mais longa em torno aos nomes de Wagner e Charles Baudelaire, os quais, como representantes da décadence, foram espíritos profundamente aparentados. Em 20 de abril de 1888, porém, uma carta a Köselitz termina por revelar, uma vez mais, que Nietzsche se ocupa de uma nova obra, mas cujo conteúdo decerto ainda soa indeterminado: "Meu dedos se ocupam de um pequeno panfleto sobre música" (N. 1022, KSB 8.298). Afora isso, no registro epistolar, só se voltará a falar sobre tal "panfleto" quando Nietzsche envia, a 26 de junho de 1888, o primeiro manuscrito ao editor Naumann, contendo a seguinte observação:

Há algo a ser impresso. Se lhe for conveniente, trataremos desse pequeno assunto imediatamente. É apenas uma brochura, mas ela deve parecer tão estética quanto possível. Diz respeito a questões da arte; por conseguinte, não devemos nos expor ao vexame com nosso gosto (N. 1052, KSB 8.342).

Com efeito, a mágoa de Nietzsche em relação a Wagner - tal como o texto d'O caso Wagner irá, depois, mostrar - não se inflamou, de modo algum, apenas em virtude de questões estéticas, senão que, sobretudo, por conta de questionamentos atinentes à visão de mundo, os quais têm a ver, em especial, com o cristianismo. 
Essa temática se acha presente não somente em obras anteriores de Nietzsche, mas também em sua correspondência. Numa carta à sua irmã do final de dezembro de 1887, o filósofo reagiu com uma clareza indisfarçável aos Ecos de Parsifal, escrito de seu então cunhado Bernhard Förster: ${ }^{2}$

Queres um catálogo dos modos de pensar que se me parecem antipódicos? Tu irás encontrá-los de forma esplendidamente concatenada nos "Ecos de Parsifal", de teu marido; quando os li, ocorreu-me a ideia arrepiante de que não compreendestes nada, absolutamente nada a respeito de minha doença, e menos ainda da minha mais dolorosa e surpreendente vivência - saber que o homem que venerava acima de tudo transformou-se, numa asquerosa degeneração, justamente naquilo que sempre desprezara mais do que tudo, a saber, na mentira apetrechada com ideais morais e cristãos (N. 968, KSB 8.218).

O libelo $O$ caso Wagner é, à primeira vista, uma obra que se consagra a Wagner e que refaz, em termos literários, a ruptura de Nietzsche em relação a este último, a qual já havia ocorrido, no âmbito pessoal, há uma década. Aos olhos do público leitor alemão, o filósofo permanecera na memória coletiva, quando muito, como um mero propagandista de Wagner, embora já tivesse se distanciado do músico inequivocadamente em alguns escritos anteriores. Todavia, em $\boldsymbol{O}$ caso Wagner, não se trata de maneira nenhuma única e exclusivamente de Wagner. A obra vale-se do compositor como um exemplo de diagnóstico da décadence, elaborada à luz de conceitos hauridos da fisiologia e da psicopatologia, terminado por ser compreendida, ademais, como um fenômeno histórico abrangente: "Eu sou, tanto quanto Wagner, o filho dessa época, o mesmo é dizer, um décadent; no entanto, compreendi isso, voltei-se contra isso" (WA/CW, Prologo, KSA 6.11). O próprio eu que

2 Cf. FÖRSTER, Bernhard. Parsifal-Nachklänge. Allerhand Gedanken über deutsche Cultur, Wissenschaft, Kunst, Gesellschaft. Leipzig, 1883; Cf. Também CAMPIONI, Giuliano; D'IORIO, Paolo; FORNARI, Maria Cristina (Orgs.). Nietzsches persönliche Bibliothek. Berlim/Nova York: Walter de Gruyter, 2003, p. 230. 
aqui toma a palavra se vê como um convalescente, ao passo que Wagner representa a doença que assola a Europa e que justifica, pois, tratá-lo como um "caso".

No início do texto, Carmen de Georges Bizet é recomendada como antídoto contra Wagner; a essa música amável e ágil faltaria completamente a afetação wagneriana; aproximar-se-ia "sem a mentira do grande estilo" (WA/CW, §1, KSA 6.13). A música teria de tornar o espírito livre - sendo que a obra de Bizet parece levar isso a cabo. Carmen dá, então, ocasião para inserir observações sobre o amor, o qual nem de longe seria tão altruísta quanto Wagner acreditaria ser. Este último é apresentado como um mestre do auto-engrandecimento, a inflar todas as coisas com a sonoridade da virtude, deixando-as sublimemente grande. Em conformidade com isso, Wagner teria variado sem trégua o problema da redenção - um problema que, em verdade, só poderia ser um problema ao décadent. Parsifal surge, então, como prova suficiente de que nos arriscaríamos a nos "sufocar mediante a ruminação de absurdos éticos e religiosos" (WA/CW, §1, KSA 6.19), tal como Nietzsche reemprega a frase gravada por Goethe sobre os românticos. Acerca do Anel dos Nibelungos, ele observa ainda como Wagner teria substituído sua crença na revolução pelo pessimismo schopenhaueriano: "Apenas o filósofo da décadence deu ao artista da décadence ele próprio" (WA/CW, §1, KSA 6.21).

A música exibiria a "degenerescência" do presente, atuando, ao mesmo tempo, como sua causa: "Em sua arte acha-se misturado, do modo mais sedutor, aquilo de que atualmente o mundo inteiro tem mais necessidade - os três grandes estimulantes dos esgotados: o brutal, o artificial e o inocente (idiota)" (WA/CW 5, KSA 6.23). Como sintoma de décadence, Nietzsche ataca a tendência de Wagner ao caótico e sua renúncia à simplicidade melódica. Como marca característica da decadência vigora a ideia de que a vida não mais determinaria o todo, impedindo, pois, que o singular pudesse nele se integrar. Credita-se então a Wagner um talento 
próprio ao "miniaturista" que, ao visar à grande forma, acabou necessariamente por se perder, por assim dizer, no interior do gênero. Interessava-lhe apenas o efeito, mas não a substância: "como músico, permanecera um retórico" (WA/CW 10, KSA 6.35). Wagner defende igualmente a proliferação do elemento teatral na música. De maneira correspondente, ao término de sua carta aberta, Nietzsche exige "que o teatro não se assenhore das artes; que o ator não se converta no sedutor dos genuínos; que a música não se converta numa arte da mentira" (WA/CW 12, KSA 6.39).0 Segundo Pós-escrito deixa claro que Johannes Brahms também não apresentaria nenhuma alternativa a Wagner, ao passo que o Epílogo volta-se, uma vez mais, ao princípio básico do texto, a saber: ao "diagnóstico da alma moderna" cuja "contradição instintual" (WA/CW, Epílogo, KSA 6.53) pode ser apresentada de forma exemplar à luz do caso Wagner

Mas $O$ caso Wagner não deve pura e simplesmente declamar, em seco tom proclamatório, as concepções de Nietzsche a respeito de Wagner, sua época e da décadence. A obra também se esforça, visivelmente, para lograr uma forma literária diversificada. A oscilação entre seriedade e jovialidade - que se anuncia, já, no mote "ridendo dicere severum"3 $(W A / C W 1$, KSA 6.13), - constitui a marca estilística pregnante do inteiro texto. $\mathrm{O}$ antigo tópos retórico-estético variatio delectat não foi, porém, empregado por Nietzsche de modo arbitrário. Fiando-se nos seus apontamentos póstumos, percebe-se que as doze seções que constituem o texto foram compostas como movimentos de uma peça musical, relacionando-se articuladamente entre si. O êxito massivo de Wagner deixa-se apreender, ali, tanto a partir do declínio característico do tipo artístico convertido num embusteiro, sua incapacidade de dar forma a uma totalidade orgânica e sua desorientação em meio aos detalhes, assim como a partir de seu

3 "Rindo, dizer coisas sérias". 
novo e artificialmente sentido fervor religioso. Quanto ao tipo de artista representado por Wagner o juízo é arrasador: não lhe seria facultado, nem de longe, superar ou transformar o ideal ascético, senão que se tornaria, antes do mais, em seu advogado e propagandista, fazendo com que a arte, segundo Nietzsche, traísse os valores da própria vida.

A música de Wagner surge, com isso, enquanto puro sintoma de decadência:

Wagner musicou apenas diagnósticos, casos muitíssimo interessantes, tipos assaz modernos de degenerescência, os quais nos são, precisamente por isso, compreensíveis. Nada é melhor estudado pelos atuais médicos e fisiólogos do que o tipo histéricohipnótico da heroína wagneriana; aqui, Wagner é especialista, chegando a ser naturalmente repulsivo nisso - sua música é, sobretudo, uma análise psicológico-fisiológica de estados doentios (Nachlass/FP, 1888, 15 [99], KSA 13.465).

Nietzsche não hesita, em virtude disso, em afirmar que "os princípios e práticas de Wagner são, em seu conjunto, reduzíveis a estados fisiológicos emergenciais: são a expressão destes últimos ('histerismo' como música)" (Nachlass/FP, 1888, 16 [75], KSA 13.510). A doença não é apenas causa, senão que também consequência de Wagner: "Tudo aquilo em que toca se torna doente - tornou a música doente" (WA/CW 5, KSA 6.21).

Nos meses restantes de sua existência consciente, Nietzsche comentou $\boldsymbol{O}$ caso Wagner diversas vezes em registro epistolar. Sua estratégia retórica consistia, pois, por um lado, em minimizar a importância de tal texto, tratando-o como um escrito de ocasião face à obra principal, a saber, à Transvaloração de todos os valores; por outro, tratava-se de atribuir-lhe, ainda assim, um papel decisivo no diagnóstico e na terapia do presente. Essa estratégia pressupõe que, mesmo uma pequena obra de Nietzsche, representaria um grande passo à humanidade. Foi com o respectivo melindre que 
Sommer, A. U.

o filósofo reagiu, em meados de outubro de 1888, quando Malwida von Meysenbug lhe denegou a aprovação por ele aguardada, privando-se do direito de exercer "franca oposição" e esclarecendo-lhe ainda:

onde acho que estais cometendo injustiça. Acredito igualmente que não devemos tratar um amor antigo, mesmo que este tenha sido apagado, tal como tratais Wagner; ofendemos, com isso, a nós mesmos, pois, em algum momento, amamos plena e verdadeiramente, sendo que o objeto de tal amor não foi, em absoluto, nenhum fantasma, senão que uma plena e efetiva realidade (N. 591, KGB III, 6.330).

Longe, porém, de aceitar a crítica amigável, em sua ríspida resposta a 18 de outubro de 1888, Nietzsche estiliza $O$ caso Wagner sob a forma de um xibolete, ${ }^{4}$ indicando como deveríamos comportar-nos em relação a ele e seu pensamento em geral:

não se trata de coisas sobre as quais permito contradição. Em questões de décadence, sou a mais alta instância que há na Terra; esses homens da atualidade, com sua lamentável degenerescência instintiva, deveriam considerar-se felizes por terem alguém que lhes presenteie com vinho puro nos casos mais sombrios (N. 1131, KSB 8.452).

A pouco amistosa carta de Nietzsche culmina, então, na oposição a um Wagner considerado "gênio da mentira", ao passo que o próprio pensador, no entanto, quer-se um "gênio da verdade" (N. 1131, KSB 8.452). Mas, mesmo diante de tal escrito, compreendido por seu autor como um "descanso", o leitor não deve comportar-se, segundo Nietzsche, de modo simplesmente indiferente ou condenatório - ainda que tal leitor fizesse parte dos antigos amigos; o juízo acerca d'O caso Wagner é estilizado como uma questão de confissão e destino.

4 Schibboleth, no original. (N.T.)

18| Cad. Nietzsche, Guarulhos/Porto Seguro, v.38, n.1, janeiro/abril, 2017. 


\section{O conceito de décadence de Nietzsche}

"O que mais profundamente me ocupou foi, de fato, o problema da décadence" (WA/CW, Prólogo, KSA 6.11). Em termos de sua história conceitual, a décadence, em Nietzsche, deixa-se compreender de modo tripartite: em primeiro lugar, desde Boileau, Montesquieu e Gibbon, a expressão é empregada, com uma conotação moral de maior ou menor intensidade, para descrever o declínio do Império Romano (a esse propósito, as Considérations de Montesquieu, obra contida na biblioteca de Nietzsche, em edição de 1836, são assaz relevantes), ${ }^{5}$ assim como para indicar - tal como, por exemplo, em Bossuet - a condição do presente. Em segundo lugar, décadence é a autopredicação de um movimento artístico em torno a Charles Baudelaire e Paul Verlaine, que elevaram, à condição de programa, a negação dos valores burgueses e a evasão das estruturas normativas burguesas ("épater le bourgeois"). Sua revista, Le décadent, veio a lume entre 1886 e 1889. ${ }^{6}$ Nietzsche encontrou o movimento literário atinente à décadence exemplarmente documentado nos (Nouveaux) Essais de psychologie contemporaine, ${ }^{7}$ de Paul Bourget. Em terceiro lugar, o uso fisiológico do vocábulo, no sentido de degenerescência, também é amplamente divulgado entre os médicos e cientistas contemporâneos de Nietzsche.

Em Wagner, contra quem Nietzsche dirige nominalmente o veredito decadencial, o conceito de décadence permanece, nas conversas com Cosima, limitado à caracterização crítico-cultural de um

5 MONTESQUIEU, Charles-Louis de Secondat, baron de La Brède et de. Considérations sur les causes de la grandeur des Romains et de leur décadence [1734], Paris, 1836. Cf. Também CAMPIONI, Giuliano; D'IORIO, Paolo; FORNARI, Maria Cristina (Orgs.). Nietzsches persönliche Bibliothek. Berlim/Nova York: Walter de Gruyter, 2003, p. 394.

6 Le Décadent: revue littéraire bi-mensuelle. Paris, janeiro de 1886 a maio de 1889. 0 periódico foi fundado por Anatole Baju. Paul Verlaine também era um dos colaboradores.

7 BOURGET, Paul Bourget, Nouveaux essais de psychologie contemporaine. Paris, 1886. Cf. Também CAMPIONI, Giuliano; D'IORIO, Paolo; FORNARI, Maria Cristina (Orgs.). Nietzsches persönliche Bibliothek. Berlim/Nova York: Walter de Gruyter, 2003, p. 148. 
declínio histórico-cíclico, assim como da preocupante decrepitude do presente, não sendo, pois, alargado até o âmbito fisiológico. ${ }^{8}$ Mas, já em 1849, nos apontamentos do inacabado $O$ gênio artístico do futuro, acha-se uma passagem - de grande interesse em vista d'O nascimento da tragédia, de Nietzsche - na qual Wagner faz intervir, com Eurípides, a ideia de uma abrangente décadence da tragédia: "Antiguidade: vai-se do coro ao indivíduo; modernidade (Shakespeare): tem início com o indivíduo. Nascimento a partir da música: Ésquilo. Décadence: Eurípides". ${ }^{9}$ Também em $O$ nascimento da tragédia, de Nietzsche, Eurípides vigora como o corruptor da tragédia, originalmente marcada pelo coro - ainda que o jovem entusiasta de Wagner não utilize, à época, o conceito de décadence.

"Sou, tanto quanto Wagner, filho desta época, o mesmo é dizer, um décadent; só que compreendi isso, voltei-me contra isso. O filósofo em mim se voltou contra isso" (WA/CW, Prólogo, KSA 6.11). A exigência de superar em si mesmo a decadência que tipificava sua época determina a autointerpretação de Nietzsche em Ecce homo, sua autogenealogia: "Descontado o fato de que sou um décadent, sou também o seu contrário" (EH/EH, "Por que sou tão sábio" 2, KSA 6.266). "O filósofo", sob a égide do qual Nietzsche se volta contra a décadence, não é, evidentemente, enquanto "filósofo", afetado pela décadence - já que, como tal, é atemporal ou se acha para além do tempo. Em contrapartida, com a exposição contida em "O problema de Sócrates", $(G D / C I$, "O problema de Sócrates", KSA 6.67-73) em Crepúsculo dos ídolos, Nietzsche deveria em breve suspeitar da decadência, não apenas esse exemplar filósofo grego, mas a filosofia em geral. A filosofia propagada no Prólogo d'O caso Wagner distingue-se fundamentalmente, ao que tudo indica,

8 Cf. WAGNER, Cosima. Die Tagebücher. Munique /Zurique, 1988, Vol. 3 (1878-1880), pp. 80, 322, 478 e 612; id. ibid., Vol. 4 (1881-1883), pp. 682, 753.

9 WAGNER, Richard. Entwürfe. Gedanken. Fragmente. Aus nachgelassenen Papieren zusammengestellt. Leipzig, 1885, p. 68; cf. CAMPIONI, Giuliano; D'IORIO, Paolo; FORNARI, Maria Cristina (Orgs.). Nietzsches persönliche Bibliothek. Berlim/Nova York: Walter de Gruyter, 2003, p. 642. 
de tudo aquilo que, até então, entendeu-se por filosofia.

Mesmo antes da leitura dos Essais de psychologie contemporaine (1883), de Paul Bourget, Nietzsche vale-se ocasionalmente do termo décadence no sentido geral de declínio, ${ }^{10}$ ao passo que, depois, seguindo Bourget, termina por compreender tal conceito sobretudo como a incapacidade, própria à época, de criar uma unidade. Esse significado inicial de décadence como um diagnóstico cultural, de cujo campo lexical obtêm-se centenas de exemplos nos póstumos e nos textos publicados, transformar-se-á, uma vez mais, no período tardio da obra, a saber: num decaimento fisiológico que parece ser tributário das ciências da natureza - sendo inclusive por estas mensurável. Os décadents, na obra de maturidade, surgem como tipos decaídos, cuja vontade se revela alquebrada e que, portanto, cultivam a vontade de nada. Estão, desse modo, alinhados com os niilistas e pessimistas. Decadência significa, sobretudo, "desagregação dos instintos" (GD/CI, "Incursões de um extemporâneo", 35, KSA 6.134), ou seja, uma dissolução da orientação e coesão dos instintos. Nietzsche sugere, aqui, que os instintos seriam algo naturalmente dado, mas que, ao longo da história civilizatória, teriam sofrido um desvio. Para compreender o discurso nietzschiano em prol de uma reabilitação dos instintos e dos impulsos não reprimidos cumpre recorrer ao seu diagnóstico segundo o qual, desde Sócrates, a filosofia teria convertido a razão numa tirana contrária aos impulsos mais poderosos. Com sua defesa dos impulsos não refreados, Nietzsche esforça-se, então, para lograr uma neutralização dessa tradição filosófica.

Por vezes, em alternativa ao conceito de décadence, Nietzsche utiliza a noção de degenerescência. Esta vem à tona, em sua obra, sob a influência da leitura do ensaio Degenerescência e criminalidade (Dégénérescence et criminalité), ${ }^{11}$ de Féré, publicado

10 Cf. Nachlass/FP, 1875-1879, 23[140], KSA 8.454; cf. carta a Overbeck de 5 de setembro de 1881 (N.146, KGB 6.127): "Sobrevivi a condições ruins; sob o influxo do clima verdadeiramente insano e maligno, adveio uma décadence generalizada".

11 FÉRÉ, Charles. Dégénérescence et criminalité. Essai physiologique. Paris, 1888; cf. 
Sommer, A. U.

em 1888. Se, de início, Nietzsche encontrou na crítica cultural e literária francesa uma pródiga fonte para a décadence, tal conceito se deixa impregnar, mais e mais, de uma acepção patológico-medicinal, recobrindo-se, por fim, amplamente, com o campo semântico atinente à degenerescência ${ }^{12}$. Enquanto Féré emprega o termo dégénérescence para descrever criminosos e doentes mentais clinicamente internados, Nietzsche transfere o conceito, numa transposição positiva do conhecimento medicinal adquirido mediante leituras, a Wagner, Sócrates e a Jesus (Cf. WA/CW 5, KSA 6.23 e AC/AC §32, KSA 6.203), invertendo, com isso, em seu contrário, a tradicional apreciação valorativa desses heróis da moral e da cultura.

Na própria obra de Nietzsche, uma aplicação estética do termo vincula-se a um uso histórico, moral e extra-moral, crítico à sua época e de cunho fisiológico-biológico: décadence significa tanto o declínio físico da espécie humana e seus indivíduos - algo ciclicamente inevitável -, assim como a produção artístico-cultural dele resultante. Décadence é a consequência de uma vontade de potência declinante e, como tal, de modo algum limitada ao presente. Pelo contrário, a história do cristianismo e do judaísmo é tratada, por exemplo, em $O$ anticristo, i. e., na "Transvaloração de todos os valores", como um fenômeno decadencial. Em meados de abril de 1886, fiando-se em Bourget e no exemplo de Wagner, Nietzsche caracteriza a décadence, em carta a Carl Fuchs, como dissolução nos detalhes: "A parte assenhora-se do todo, a frase da melodia, o instante do tempo" (N. 688, KSB 7.177). E não se esquece de acrescentar: "há também, na décedence, uma soma enorme daquilo que é mais atraente, valioso, novo e venerável - nossa música moderna, por exemplo" (N. 688, KSB 7.177).

CAMPIONI, Giuliano; D'IORIO, Paolo; FORNARI, Maria Cristina (Orgs.). Nietzsches persönliche Bibliothek. Berlim/Nova York: Walter de Gruyter, 2003, p. 223.

12 Isso se torna patente nos fragmentos póstumos de 1888, como, por exemplo, 14[73], [74] e [75] (KSA 13. 255) - sendo que, em 14 [75], trata-se de uma paráfrase direta do livro de Féré. 
III. Decadência e O caso Wagner no quadro geral da filosofia de Nietzsche

O caso Wagner é um escrito de ocasião, o qual Nietzsche decerto não tencionava considerar uma de suas obras principais. No entanto, em Ecce homo, dedica à obra um capítulo que é mais longo do que o conjunto das retratações, ali contidas, de Além de bem e mal, Para a genealogia da moral e Crepúsculo dos ídolos. Além disso, como obra única, $O$ caso Wagner não é tratado, em Ecce homo, em conformidade com a cronologia de surgimento e publicação dos demais escritos, senão que ocupa o último lugar, depois de Crepúsculo dos ídolos - texto posteriormente concluído e preparado para a publicação apenas mais tarde -, assumindo, com isso, uma posição de destaque (Cf. EH/EH, "O caso Wagner" 1-4, KSA 6.357-364). Desse modo, a obra adquire uma importância que Nietzsche trata de justificar a partir de seu próprio sofrimento: "De que sofro, quando sofro do destino da música? Do fato de que se lhe tiraram o caráter mundialmente transfigurador, afirmador" (EHEH, “O caso Wagner" 1, KSA 6.357). Em sua retratação d'O caso Wagner, no entanto, Nietzsche não fala nem acerca do principal tema do livro nem fornece uma explicação a respeito de sua crítica a Wagner. Demora-se, antes do mais, na exposição dos horrores que os alemães teriam cometido na história da cultura europeia.

Essa omissão em relação a Wagner parece indicar que, em $O$ caso Wagner, trata-se apenas superficialmente de um acerto de contas pessoal, referindo-se, em verdade, a um caso exemplar de uma efetiva transvaloração, à qual Wagner e a música dão somente o ensejo externo. Em termos de seu conteúdo, os argumentos apresentados em $O$ caso Wagner contra o compositor alemão são plenamente conhecidos a partir de escritos anteriores de Nietzsche, mas apenas no recrudescimento polêmico de 1888 eles surgem como elementos de uma estratégia geral, a qual visa a decretar ao presente uma nova orientação valorativa, a saber, a afirmação 
antidecadencial da vida. Essa afirmação consiste numa renúncia fundamental à orientação espiritual e metafísica que Nietzsche atribui à cultura ocidental com sua infecção cristã. Com isso, a moralidade deve ser completamente deslocada, de sorte que as virtudes supostamente servis tais como, por exemplo, humildade ou compaixão devam ser substituídas por virtudes nobres tais como bravura e coragem.

Por um lado, O caso Wagner teria sua importância como um caso de aplicação do conceito de "transvaloração dos valores." Por outro, uma intenção central do escrito consiste em eliminar toda confusão entre Nietzsche, Wagner e as ideias de renovação cultural esposadas por este último. $\mathrm{O}$ medo de ser confundido é uma marca específica dos textos de 1888 (EH/EH, Prólogo 1, KSA 6.257). A Nietzsche parece que somente uma retórica furiosa e isolante poderia ajudar a conjurá-lo. Com $O$ caso Wagner lhe foi facultado, sem dúvida, sair da sombra de Wagner. Sua recepção imediata e intensiva faz de tal escrito um ponto de sinalização importante na história da repercussão de Nietzsche.

Mas, estaria Nietzsche certo em seu diagnóstico da decadência? E, supondo que sim, podemos estar seguros de que ele, de fato, superou a decadência em si mesmo?

\begin{abstract}
The Wagner/décadence binomial is fundamental to comprehend and characterize Nietzsche's latest philosophy, for it outlines, on the one hand, the negative and disruptive side of his critique on aesthetic modernity; and, on the other, it makes possible a precise application of the so called "transvaluation of all values." Attentive and responsible, this article aims at explaining this double point of view.
\end{abstract}

Keywords: Wagner - Nietzsche - décadence - transvaluation of all values 


\section{Referências bibliográficas}

BOURGET, Paul Bourget, Nouveaux essais de psychologie contemporaine. Paris, 1886.

CAMPIONI, Giuliano; D'IORIO, Paolo; FORNARI, Maria Cristina (Orgs.). Nietzsches persönliche Bibliothek. Berlim/Nova York: Walter de Gruyter, 2003.

FÉRÉ, Charles. Dégénérescence et criminalité. Essai physiologique. Paris, 1888.

FÖRSTER, Bernhard. Parsifal-Nachklänge. Allerhand Gedanken über deutsche Cultur, Wissenschaft, Kunst, Gesellschaft. Leipzig, 1883.

MONTESQUIEU, Charles-Louis de Secondat, baron de La Brède et de. Considérations sur les causes de la grandeur des Romains et de leur décadence [1734], Paris, 1836.

NIETZSCHE, Friedrich. Sämtliche Werke. Kritische Studienausgabe (KSA). Berlim/ Nova York: Walter de Gruyter, 1999.

. Briefwechsel. Kritische Gesamtausgabe (KGB). Berlim/Nova York: Walter de Gruyter, 2003.

. Sämtliche Briefe. Kritische Studienausgabe (KSB). Berlim/Nova York: Walter de Gruyter, 1999.

SOMMER, Andreas Urs. Kommentar zu Nietzsches Der Fall Wagner. In: GötzenDämmerung (Historischer und kritischer Kommentar zu Friedrich Nietzsches Werken von der Heidelberger Akademie der Wissenschaften), Bd. 6/1), Berlim/Boston: de Gruyter, Vol.6/1, 2012.

WAGNER, Richard. Entwürfe. Gedanken. Fragmente. Aus nachgelassenen Papieren zusammengestellt. Leipzig, 1885.

Artigo recebido para publicação em 16/10/2016.

Artigo aceito para publicação em 23/11/2016. 